\title{
O GALEGO, PATRIMONIO COMÚN
}

\author{
Xosé Manuel Villanueva
}

Universidade de Santiago de Compostela 

A normalización do uso do galego púxose no primeiro plano da actualidade como conflito político cando o consenso xeral, establecido xa en 1983 coa aprobación da Lei (3/1983, do 15 de xuño) de normalización lingüística e ratificado vinte e un anos despois (o 21 de setembro de 2004) coa unánime aprobación no Parlamento de Galicia do Plan xeral de normalización da lingua galega, rachou en 2007 arredor do Decreto (124/2007 do 28 de xuño) regulador do uso do galego no ensino. A fenda agrandou polo tratamento da cuestión da lingua no proceso electoral de 2009. Por primeira vez nunhas eleccións autonómicas un partido con aspiracións de goberno asumiu como obxectivo propio mudar normas e actitudes nese eido para acabar coa imposición do galego que os excesos no proceso normalizador estaban a supoñer. Eses excesos, concretados sobre todo no uso escolar do galego, entendíase que afectaban á liberdade lingüística individual e supoñían discriminar os castelanfalantes. A cousa pintábase tan dramática que o desexo da base social que alimentou esa posición política consistía en garantir que Galicia se mantivese bilingüe xa que mesmo a supervivencia nos nosos lares do castelán estaría ameazada.

O debate así formulado remítenos a un imaxinario no cal Galicia, en termos lingüísticos, sería (poñamos por caso) Bélxica: unha sociedade dividida en comunidades lingüísticas cuxo status fronte ás institucións e ás outras comunidades é necesario delimitar. Así, o galego sería a lingua dos galegos, lingua dominante adoptada como propia polo poder político de forma excluínte, o castelán a lingua dos españois que viven en Galicia, acantoada nun espazo cada vez máis reducido e con maiores dificultades para desenvolverse, e a política lingüistica, xa que logo, un elemento indispensable para ordenar a convivencia desas dúas comunidades, entre si alleas e conflitivas.

Ese imaxinario, tan debedor da visión mesetaria da cuestión lingüística española, resultou eficaz xa que se asenta sobre a convicción de boa parte das clases medias urbanas de Galicia de que o galego é unha lingua inútil, rural e sen futu- 
ro, e o seu rexistro culto un "enxendro" de laboratorio, un ridículo capricho polo que non paga a pena gastar enerxías nin tempo. Tal corrente de fondo está presente na sociedade galega desde sempre, e durante os longos anos do consenso lingüístico foi algo así como un baixo continuo de cando en vez axitado por políticos varios con rendementos electorais evidentes, pero cuxo uso ficaba escurecido pola corrección política das respectivas organizacións. Eran cousas de xan ou de pericán, pero non a liña do partido.

O salto cualitativo producido nas eleccións pasadas é que agora, sen disimulos, o partido gañador e actual responsable do goberno da Xunta (pero ao mellor non só el) coida que o esencial da actuación lingüística dos poderes públicos xa non é tanto a normalización do galego como asegurar, especialmente no campo do ensino e da Administración, que o castelán e os seus falantes sexan perturbados o menos posible pola leria esta da lingua propia coa que temos que cargar. Se se quere, liberar os galegos castelanfalantes da súa responsabilidade na normalización do galego. Converter a participación dos cidadáns nese proceso normalizador en algo voluntario: facelos libres non tanto de usar o castelán (cousa nunca posta en cuestión) senón de participar ou non no proceso normalizador do galego.

A relación entre ese feito excepcional e os resultados da enquisa sobre o uso do galego feitos públicos hai pouco polo Instituto Galego de Estatística (IGE) é, ao meu xuízo, interesante en dous sentidos: o primeiro, porque ratifica a delirante imaxe da realidade sociolingüística de Galicia que alicerza os discursos sobre a imposición do galego; o segundo, porque revela os limitados resultados da acción normalizadora froito da época do finado consenso e, en consecuencia, como nestes últimos vinte anos se ampliou a poboación allea ao compromiso co galego e, xa que logo, o electorado potencialmente sensible a propostas antinormalizadoras.

Os datos son coñecidos e indican que de 2003 (momento anterior á aprobación do Plan xeral de normalización da lingua galega) a 2008:

1) O galego retrocedeu, perdeu posicións:

A poboación maioritariamente galegofalante retrocede do 61,2 ao 57\% (os falantes exclusivos en galego pasaron do 43 ao 30,3\% —un 12,7\% menos-, e os que falan máis galego que castelán do 18,2 ao $26,7 \%$ —un $8,5 \%$ máis). 
A perda de galegofalantes é moi superior nos tramos de idade máis novos (dos menores de 15 anos só falan galego o 15,3\% fronte ao 29,6\% que só fala castelán —un diferencial do 14,6\%—, e o 20,9\% fala máis galego que castelán fronte ao $34,3 \%$ que fala máis castelán que galego —un diferencial do 13,4\%). Así, nos menores de 15 anos os maioritariamente galegofalantes son o $36,2 \%$, un 20,8\% menos que a media de toda a poboación.

Finalmente, o contorno urbano, coa excepción de Santiago de Compostela, decántase claramente polo uso preferente do castelán (os que o falan en exclusiva ou preferentemente son o $81 \%$ en Ferrol, o $74 \%$ en Vigo, o $72 \%$ na Coruña).

2) $O$ grao de bilingïismo da sociedade galega acrecentouse significativamente en favor do uso do castelán, de xeito que se o $75,54 \%$ da poboación maior de 65 anos fala galego sempre, o $15,50 \%$ ás veces e só o $8,95 \%$ nunca, o $44,3 \%$ dos menores de 35 anos falan galego sempre, o 40,30\% fálano ás veces e o 15,37\% non o falan nunca.

3) A transmisión inicial da lingua diminuíu de xeito significativo, especialmente no ámbito urbano, de xeito que entre un 15 e un $27 \%$ dos rapaces menores de 10 anos que viven en núcleos urbanos nunca falan o galego, e entre un 10 e un 20\% chegan mesmo a non sabelo falar (PXNL).

4) Pola contra, o grao de competencia lingüistica dos habitantes de Galicia mellorou tamén significativamente, como se deduce destes datos:

\begin{tabular}{lllll} 
Total & Entenden & Falan & Len & Escriben \\
\hline 1991 & $96,96 \%$ & $91,39 \%$ & $49,30 \%$ & $34,85 \%$ \\
\hline 2001 & $99,16 \%$ & $91,04 \%$ & $68,65 \%$ & $57,64 \%$ \\
\hline Diferenza & $+2,20 \%$ & $-0,35 \%$ & $+19,35 \%$ & $+22,79 \%$ \\
\hline
\end{tabular}

Unha lectura da combinación destes catro factores pode levarnos a realizar polo menos estas catro afirmacións:

a) A acción pública ten límites para contrarrestar fenómenos sociais que xogan a prol da extensión do uso do castelán. Ás veces non somos capaces de calibrar, metidos no espazo dunha análise limitada, as forzas que están a desencadearse ao noso arredor e que mudan a escala das batallas e, en consecuencia, as armas que é necesario poñer en xogo. 
b) Por esa ou por outras razóns, as medidas xestadas baixo a protección do consenso non foron suficientes para frear a diminución do uso do galego, aínda que, obviamente, se non existisen esas actuacións de protección a situación estaría aínda máis degradada.

c) A eficacia da aprendizaxe escolar do galego non asegura a xeneralización do uso social da lingua.

d) En todo caso, o galego segue a ter unha gran forza e o seu uso esténdese a unha amplísima maioría da poboación de Galicia: por uso preferente $(57 \%)$ ou ocasional $(22,7 \%)=79,7 \%$, e a súa comprensión á práctica totalidade da poboación $=99,16 \%$.

En moitas ocasións, e non só no plano lingüístico, dá a sensación de que os grandes consensos políticos serven como disfraces, como carautas que permiten agochar baixo a ausencia de confrontación comportamentos contraditorios que, voluntaria ou involuntariamente, flúen á marxe e medran. Esa contradición pode explicar que nun momento dado o custo de satisfacer demandas de colectivos, mobilizados pero minoritarios, contrarias co defendido historicamente por un partido e, mesmo, co sentimento maioritario dos seus seguidores, sexa nulo: a feble esixencia dos interesados na defensa de algo non é abonda para contrarrestar os efectos electoralmente positivos da cesión aos que o rexeitan. E cando iso sucede é totalmente necesario redefinir os termos dese ficcional consenso xeral.

Por concretar, os datos achegados polo IGE indican que a cuestión lingüística que se está a dilucidar en Galicia non é a normalización do galego entendida como a súa instalación como lingua única e dominante, nin moito menos o risco de extinción entre nós do castelán; na miña opinión, a cuestión tampouco é se o galego vai morrer ou desaparecer, senón como vai perdurar esa fráxil creación cultural desta fisterra europea convivindo xa non no mesmo territorio, senón nos mesmos falantes, co poderosísimo castelán.

A resposta a esa pregunta acepta dous escenarios alternativos: o galego pode converterse nunha lingua folclorizada, reducida a un uso ritual e cultural, como un prezado resto arqueolóxico; ou pode manterse como unha lingua de uso e comunicación xeral, como unha realidade viva e creativa en relativa comparación co castelán, e esta dicotomía trasládanos inevitablemente ao campo das cuestións que afectan ao patrimonio histórico e cultural. 
En efecto, os bens patrimoniais poden dividirse en dous grupos: os que tendo perdido a súa función e vixencia orixinarias se manteñen como un fermoso testemuño do pasado (como, por exemplo, o conxunto de Angkor en Cambodia); e os que, ademais de preservaren o seu valor histórico, mantiveron tamén o seu uso e función (como sucede, por exemplo, coa cidade histórica de Santiago). E, nestes últimos, a política patrimonial debe ir dirixida non tanto á preservación física do ben monumental (cousa que se dá por suposta), senón a manter a súa vitalidade e uso.

É sabido que as linguas poden ser vistas desde a perspectiva patrimonial, e non só desde a das políticas lingüísticas. A conferencia mundial da UNESCO sobre o Patrimonio Cultural, realizada en México no ano 1982, estableceu que «O Patrimonio Cultural dun pobo comprende as obras dos seus artistas, arquitectos, músicos, escritores e sabios, así como as creacións anónimas, xurdidas da alma popular, e o conxunto de valores que dan sentido á vida, é dicir, as obras materiais e non materiais que expresan a creatividade dese pobo; a lingua, os ritos, as crenzas, os lugares e monumentos históricos, a literatura, as obras de arte e os arquivos e bibliotecas».

Tal perspectiva foi incluída no artigo 23 da Lei 3/1983, do Parlamento de Galicia de normalización lingüística, inserido no título VI «Da administración autonómica e a función normalizadora». $\mathrm{O}$ artigo di: "O goberno galego establecerá un plan destinado a resaltar a importancia da lingua como patrimonio histórico da comunidade e a poñer de manifesto a responsabilidade e os deberes que esta ten respecto da súa conservación, protección e transmisión».

Malia este mandato, en Galicia o discurso político afondou na análise da cuestión da lingua desde a perspectiva sociolingüística e de construción política do país, e menos desde a perspectiva patrimonial.

Falar desde unha e outra perspectiva non é que mude moito a realidade. Boa parte do problema subsiste porque as nosas clases medias urbanas teñen tendencia a ser, na mesma medida que antigalegas, antipatrimoniais. A burguesía, en termos históricos, deu carta de natureza ao pensamento liberal (a liberdade de empresa, a lexitimidade do uso dos recursos por parte da xeración presente e, xa que logo, da expansión do capital e do dereito ao espolio), pero tamén ao pensamento romántico (a idea da descontinuidade do progreso, o interese pola preservación da identidade, a importancia da sostibilidade e da perspectiva do mantemento no tempo dos bens actuais). A clase media urbana galega, maiori- 
tariamente insensible aos cultismos románticos, vive, especialmente desde a Guerra Civil, asentada na cultura do espolio, que se reflicte de xeito moi visible na realidade dos territorios e das cidades, pero, tamén, no rexeitamento dos discursos culturais de orixe autóctona que pretendan superar o folclórico.

Non obstante, o tema patrimonial xera contradicións e achega novas lexitimidades, porque, obviamente, negar a relevancia dos bens patrimoniais pon en cuestión o nivel cultural dunha sociedade e desmerece, en parte, o padrón das boas formas e do prestixio social actualmente común no noso contorno internacional. $\mathrm{O}$ uso táctico dese recurso foi moi visible no enroque que arredor da festa dos touros supuxo a proposta da Comunidade de Madrid de a considerar Patrimonio Cultural.

É certo que as linguas son bens patrimoniais moi especiais, xa que a súa materialización non é, como a dos monumentos ou as obras de arte, autónoma a respecto das persoas senón que as compromete de xeito directo, e aí, no plano das persoas, mestúrase con moitas outras visións, valores e necesidades (a capacidade de expresión, a comodidade, o exercicio da liberdade de opción) que poden facer compatible no individual o respecto ao ben e o seu non uso. Pero, en calquera caso, insistir na dimensión patrimonial da lingua, no seu significado como capital cultural acumulado, debe ser unha parte fundamental da cuestión.

Desde outra perspectiva, a valoración patrimonial é máis próxima ao afecto, ao sentido de identidade e pertenza, que é un factor básico para o futuro da lingua: a lingua como algo realmente propio, que, ao tempo, nos caracteriza e singulariza. Esa implicación afectiva é, cando menos, tan indispensable como o coñecemento académico. Non é bo esquecer que a subsistencia e a reivindicación do galego tras os longos séculos escuros ten que ver con ese sentido patrimonial. Era a nosa lingua, esa que, aínda que non se quixese normalizar como lingua de uso culto, era a que realmente usabamos. Ao falar galego, eramos nós mesmos. E a demostración de que a incorporación do galego ao ensino non abonda hoxe para manter as taxas de uso na poboación máis nova (que coñece a lingua pero que non a usa habitualmente no mesmo grao que as xeracións en que o galego non existía no mundo académico) fai pensar en que a comprensión por parte da xente nova da significación patrimonial da lingua é unha necesidade inadiable. 
Pois ben, as políticas patrimoniais están a evolucionar en relación cos bens que se configuran como bens vivos. Evitar a monumentalización e soster a vitalidade é o cerne da cuestión, cousa bastante semellante aos requirimentos da cuestión do galego. A análise de como se artellan esas políticas no concreto, por exemplo no caso da cidade de Santiago, pode ter utilidade, por analoxía, para considerar novas esixencias das políticas de protección e promoción do galego.

As políticas patrimoniais tradicionais artéllanse sobre estas bases:

\section{A identificación do ben que hai que protexer}

Esta é unha cuestión fundamental. Parte da lexitimidade e eficacia das accións posteriores dependen da corrección e rigor nesa fase descritiva. Ese é o momento en que coñecementos técnicos e sentido social e político casan para definir e xerar toda a política de protección. No caso de Santiago (dunha cidade calquera) iso concrétase, por un lado, na avaliación da calidade dos elementos constitutivos da construción (as edificacións en si, pero tamén a súa traza e distribución) pero, por outro, na relación do construído cos baleiros, coa paisaxe circundante.

a) En Santiago, cada un dos edificios dos 2600 que forman a cidade histórica foi analizado para establecer a súa catalogación e o nivel de protección requirido en función do seu valor, reflectido en 4 graos, desde aquel que supón unha protección integral ao que se concreta no interese do edificio no conxunto urbano e, en consecuencia, a mera preservación da súa configuración exterior e da súa tipoloxía arquitectónica. Desa análise, 1750 edificios foron catalogados.

b) Pero en Santiago dábase outra compoñente para a fixación do ben que hai que preservar: a relación da cidade co seu contorno natural máis inmediato. De xeito case milagroso, as áreas de contorno da cidade histórica, agás a do sur, mantivéronse libres de construcións, polo cal existía a posibilidade de incorporar eses espazos baleiros ao ben patrimonial protexido. A decisión supuxo coutar moitas expectativas de negocio, pero asentou o valor do ben, xa que a insaciabilidade construtiva dos nosos promotores tería conducido, probablemente, a unha colmatación edificatoria das hortas e os espazos naturais como a que de feito se produciu a carón dos límites do termo municipal. 
c) A suma dos dous factores permitiu delimitar o ben que hai que protexer e codificalo nun mapa concreto e estable.

No caso da lingua, o factor similar ao da delimitación do ben é o da normativización. Neste campo traballouse moito desde os anos 60 do século pasado na análise lingüística, no traballo de campo e no decantamento das formas maioritarias; tardouse demasiado na definición dun marco normativo estable (acordo ortográfico de 2003) logo de máis de 20 anos de polémicas e deslexitimacións entre paradigmas pragmáticos ou históricos, e, cando se pechou o marco normativo, as alternativas que se deixaron abertas como froito do consenso técnico foron usadas no político dun xeito desolador para o obxectivo normalizador: o paradigma foi o binomio Galicia, Galiza que nos regalou o goberno bipartito. Neste asunto hai unha tendencia, permanente en todo o proceso recente, de usar a norma como un factor de diferenciación e establecemento do nivel de galeguidade de grupos e correntes, algo así como unha escala de pedigree, que na miña opinión é profundamente negativa.

A normalización da norma segue a ser esencial. Asentar o padrón normativo sobre as bases existentes e deixar supeditado o desenvolvemento e evolución futura da norma, por medio das innovacións e adaptacións necesarias, á prioridade da normalización paréceme fundamental.

\section{A súa posta en valor}

Parte do éxito da actuación protectora sobre a cidade de Santiago dependeu da súa posta en valor por medio de recoñecementos formais, propios e alleos, e pola comprensión colectiva da relevancia económica do ben protexido.

En Compostela, o fito máis salientable neste sentido foi a declaración como Patrimonio da Humanidade (1985), o Premio Europeo de Urbanismo (1997) e, quizais, a designación como Cidade Europea da Cultura (2000). Existe un fenómeno psicolóxico que asocia a conciencia do valor a como o valor do propio é percibido polos alleos.

Pero o feito decisivo foi a constatación empírica de que o valor patrimonial é un valor económico, un factor de desenvolvemento. En Compostela, tal constatación pasou a ser indiscutida a partir do ano 1993, cando o proxecto proteccionista da cidade histórica se viu claramente asociado ao proxecto de expansión e crecemento 
urbano derivado do plan xeral de 1989, e que nos anos sucesivos tivo unha clara materialización nas cifras de actividade económica e emprego.

No campo da lingua, na miña opinión aí hai moito camiño por percorrer tanto nun sentido coma no outro, e especialmente nun aspecto que se argumenta como un activo e que non se acaba de materializar na sensibilidade e nas experiencias propias e alleas: a pertenza (ou inclusión) do galego como membro valorizado da comunidade lusófona.

\section{A súa protección normativa}

Obviamente, un ben prezado debe ser preservado por disposicións xurídicas. A cidade de Santiago é un ben conxunto, no que o valor da totalidade materialízase nunha pluralidade de elementos e de donos. Así, a única forma de preservar o patrimonio público é establecer restricións aos dereitos de disposición das múltiples propiedades privadas en que aquel se descompón, ampliando as obrigas asociadas a ese dereito e regulando de forma específica materias que noutros ámbitos non o necesitarían. Por exemplo, en interese de todos, os propietarios dos edificios da cidade histórica de Santiago de Compostela, en función do nivel de protección definido nos seus bens, non poden alterar, como xa comentamos, os volumes das súas casas, usar nelas determinados materiais ou desenvolver determinados usos, e é que a preservación do patrimonio esixe esforzo, deberes, gastos e, tamén, unha actitude culta, madura, que forza a renunciar a expectativas inmediatas e persoais para asegurar beneficios futuros e colectivos.

A resistencia de certos propietarios a asumir esas cargas seméllase ás protestas daqueles que denuncian as medidas que impoñen o galego sobre o castelán: un rexeitamento á relevancia do ben que hai que preservar e a como esa preservación afecta ao seu ámbito persoal. E, para tales rexeitamentos, os excesos (que habelos hainos) convértense en categoría.

Non obstante, a perspectiva patrimonial explica que, no plano lingüístico, as obrigas de coñecemento escolar do galego e as de coñecemento da lingua para os empregados administrativos e públicos (en xeral) teñen a mesma lexitimidade que as que se lles demandan aos propietarios dun edificio catalogado da cidade histórica de Compostela. Non se discrimina de forma inxusta a un aspirante a funcionario ao lle esixir o coñecemento do galego porque ese é o xeito de asegurar desde a Administración o dereito xeral dos cidadáns a seren atendidos nesa lingua, do mesmo xeito 
que impedir actuacións que muden o ben catalogado garante o dereito colectivo de gozo dun ben de valor artístico ou histórico. Non se impón o uso da lingua establecendo a obriga curricular de aprendela, como tampouco se pode considerar unha imposición ilexítima aprender matemáticas ou ciencias sociais, ou esixir ao propietario dun monumento o seu mantemento ordinario.

\section{O fomento da súa conservación e uso}

Esas obrigas van acompañadas, no caso de Santiago de Compostela, do apoio público ás actuacións de rehabilitación, é dicir, da asignación de recursos colectivos para compartir os custos privados da conservación dun ben de interese público. Esta cuestión resúmese ben no concepto que define a unha cidade histórica como un Patrimonio público de multi-propiedade privada.

No caso da lingua, as accións de fomento dese Patrimonio común intanxible materializado a través da acción persoal dos individuos concrétase en medidas xa coñecidas, como a existencia de medios de comunicación públicos en lingua galega, a axuda á creación e edición literaria, o apoio aos estudos lingüísticos, a extensión cultural, sufragar os custos de servizos de tradución para asegurar a presenza da lingua en institucións e eventos, etc.

Esa política usa ferramentas potentes e responde aos padróns habituais da acción pública: regular, vixiar e fomentar. Diriamos que a imaxe que ilustra mellor a súa formulación é a dun camiño de ferro. Decídese un itinerario, constrúese a vía e ponse sobre ela unha locomotora que tira duns vagóns aos que se soben os que queren ir nesa dirección. Os viaxeiros son levados cara ao seu destino sen máis esforzo que sacar o billete. Son as accións que nacen desde o poder entendido como potestas, como recurso dotado de capacidade activa e coercitiva.

Non obstante, no que atinxe aos bens patrimoniais, cada vez é máis evidente que as accións baseadas no poder, sendo esenciais, non son suficientes. As dinámicas da realidade social e económica operan con fluxos e inercias que superan o ámbito decisional das administracións. Os feitos desenvólvense con lóxicas e recursos que superan os compartimentos estancos e as fórmulas convencionais de actuación pública.

As novas políticas de protección patrimonial pivotan sobre bases moito máis fráxiles e sutís. A cuestión xa non é a preservación física da cidade ou o recoñe- 
cemento normativo do status da lingua (o que se dá por suposto), senón o uso, as funcións e a actualización e renovación vivas de ambas: no caso da cidade, conseguir que sexa vivida, non monopolizada por funcións alleas á súa natureza, non esquilmada na súa alma polo seu uso como recurso económico; no caso da lingua, mellorar a forma como se transmite o seu coñecemento, como se concreta o seu uso nos distintos eidos da vida social, como se vive e coñece a súa significación cultural e comunicativa, e xa non só no seo da comunidade que a fala, senón nos espazos lingüísticos cos que se relaciona.

Iso formula tres novas esixencias:

A primeira, dispoñer de información operativa (é dicir, de datos periódicos) sobre a evolución dos nosos propósitos.

Este é un xeito de regular e orientar os debates e as decisións. Boa parte do universo ideolóxico da polémica sobre o galego producida antes das eleccións tería sido anulada de dispoñer de algo así como o Índice de Proliferación do Galego (o IPG), que debería publicarse anualmente como tantos e tantos indicadores que determinan a nosa actuación política e social e que van marcando os ritmos dos esforzos e das actuacións (o IPC, o PIB, a EPA). Imaxinan o útil que sería para centrar a cuestión real da lingua e poñer no seu sitio a idea da imposición do galego poder afirmar que o IPG no período interanual de 2008 a 2009 diminuíu o 1,3\% no conxunto da poboación e que entre os menores de 15 anos acadou o máximo histórico do 3\%?

Ese IPG podería descompoñerse en varios subíndices, que medisen a penetración da lingua en áreas funcionais concretas (o comercio, os medios de comunicación) ou por cortes de idade; tamén podería completarse con estudos sobre a calidade do galego empregado en distintos ámbitos que permitise orientar accións de promoción e formación especificamente dirixidas.

No plano das cidades históricas estanse a construír indicadores semellantes sobre o estado da edificación, o grao de equipamentos e infraestruturas dispoñibles, o grao de ocupación residencial, índices de poboación residente e transeúnte, grao de actividade económica, etc. que están sendo conformados polos organismos internacionais (UNESCO e Centro de Patrimonio Mundial) como protocolos normalizados para analizar a evolución efectiva das políticas de protección. 


\section{A segunda é a implicación social.}

Pode parecer unha contradición, mesmo un retroceso, pero hai que consideralo xusto en sentido contrario. Durante moito tempo o obxectivo esencial dos defensores do patrimonio (mesmo o lingüístico) consistía en comprometer os poderes públicos nesas actuacións. Hoxe, a evolución social pon de relevo que o esencial é como a sociedade se mobiliza e compromete arredor da protección patrimonial. $\mathrm{O}$ futuro real dos bens patrimoniais atópase nas actitudes e comportamentos das sociedades que os posúen e custodian. No caso da lingua iso é aínda máis evidente. A toma de consciencia social do valor patrimonial (é dicir, histórico, cultural, e identitario) dun ben e a súa relevancia como activo cultural e económico son fundamentais.

Nas nosas sociedades hai o risco de reducir eses procesos ao debate político. Pero a realidade é que a batalla se xoga máis no plano social. A concepción da política como vangarda é, na conxuntura presente, unha quimera, un resto arqueolóxico, un monumento. Actualmente a política tende máis a responder ás correntes sociais que a conformalas. Se a sociedade demanda algo, terá unha resposta política. Se unha demanda social minoritaria achega máis beneficio que custo a causa da feble tensión social da maioría, acabará tendo satisfacción política.

Pero a tensión social arredor das cuestións patrimoniais non se acada desde a visión político-partidaria. Só a busca de alianzas socialmente amplas, a mobilización sobre bases culturais de toda a sociedade (desde os galegofalantes ata os castelanfalantes) e a actuación sabia de institucións prestixiadas e suprapartidarias farán posible ese proceso de responsabilización activa da colectividade.

\section{A terceira é conseguir a transversalidade e coordinación das accións e das politicas} interinstitucionais.

No campo específico da xestión pública, cada vez máis a actuación patrimonial supera o plano sectorial ou específico. As accións requiridas deben repousar sobre a interrelación das distintas políticas sectoriais e sobre a coordinación e corresponsabilidade dos distintos niveis de Administración en exercicio das súas competencias. No caso das cidades históricas, o reto está máis en como integrar a visión patrimonial nas políticas de vivenda, de infraestruturas, de promoción turística, de atención social, de renovación enerxética, etc. que en intensificar a 
mera actuación patrimonial. Tamén en como integrar os niveis de competencia local, autonómica e estatal en políticas estruturadas.

No caso da lingua, probablemente sexa necesaria unha orientación semellante, onde as demandas de protección da lingua se integren nas actuacións sectoriais propias do campo económico, territorial, social ou cultural e a totalidade dos niveis político-administrativos se usen máis para a súa defensa e promoción.

En calquera caso, iso xa non se pode conseguir só coas ferramentas potentes da Administración, senón con instrumentos fráxiles e sutís que fundamenten a súa eficacia na influencia máis que na xestión. A vangarda do proxecto de protección patrimonial xa non se pode concibir como un convoi ferroviario, senón máis ben como un veleiro sucando o mar e adaptando a súa singradura a ventos e mares potentes e cambiantes: os instrumentos de medición darán ollos á viaxe, a tripulación será parte activa desta, e a competencia do patrón será a que lexitime a súa función directiva.

A clave está no poder entendido máis como auctoritas que como potestas, e a auctoritas non se gaña só (nin principalmente) no campo da acción política. En Galicia, temos moitos exemplos históricos diso porque, non o hai que esquecer, o galego viviu longos séculos afastado do poder, negado por el. A integración cooperativa de coñecementos, de sensibilidades e de valores arredor da lingua é o que pode establecer unha efectiva mobilización social para o uso e promoción do galego. E aí as institucións non partidarias (a RAG e o CCG, por exemplo), de se manter como tales e de se cargar de auctoritas, poden desempeñar un papel cada vez máis importante.

\section{CONCLUSIÓN}

O galego é un patrimonio cultural que merece o noso esforzo para asegurar a súa permanencia como instrumento vivo de comunicación e non como vestixio da historia, e iso implica que todos os galegos (tamén os castelanfalantes) debamos asumir de forma natural responsabilidades individuais de aprendizaxe e uso, e deberes esixibles legalmente. Pero o futuro da lingua, moito máis que da 
regulación política e da acción administrativa, depende de como os cidadáns de Galicia a aprecien e a incorporen ao seu acervo como un ben non connotado partidariamente; de como o feito lingüístico se integre nunha vivencia cultural ampla e comprometida co patrimonio que atesouramos, que nos singulariza e nos une.

Cidadáns e políticos deberiamos poñernos urxentemente a iso porque, lamentablemente, niso non estamos. 